\title{
Review Article \\ Influenza Virus Aerosols in the Air and Their Infectiousness
}

\author{
Nikolai Nikitin, Ekaterina Petrova, Ekaterina Trifonova, and Olga Karpova \\ Department of Virology, Lomonosov Moscow State University, 1/12 Leninskie Gory, Moscow 119234, Russia \\ Correspondence should be addressed to Nikolai Nikitin; nikitin@mail.bio.msu.ru
}

Received 21 May 2014; Revised 11 July 2014; Accepted 25 July 2014; Published 13 August 2014

Academic Editor: Stefan Pöhlmann

Copyright (C) 2014 Nikolai Nikitin et al. This is an open access article distributed under the Creative Commons Attribution License, which permits unrestricted use, distribution, and reproduction in any medium, provided the original work is properly cited.

Influenza is one of the most contagious and rapidly spreading infectious diseases and an important global cause of hospital admissions and mortality. There are some amounts of the virus in the air constantly. These amounts is generally not enough to cause disease in people, due to infection prevention by healthy immune systems. However, at a higher concentration of the airborne virus, the risk of human infection increases dramatically. Early detection of the threshold virus concentration is essential for prevention of the spread of influenza infection. This review discusses different approaches for measuring the amount of influenza A virus particles in the air and assessing their infectiousness. Here we also discuss the data describing the relationship between the influenza virus subtypes and virus air transmission, and distribution of viral particles in aerosol drops of different sizes.

\section{Introduction}

Influenza is one of the most contagious and rapidly spreading infectious diseases and an important global cause of hospital admissions and mortality [1]. Influenza virus concentration $[2,3]$, air circulation time, air temperature, and humidity [4] play an important role in overcoming the epidemic threshold.

Influenza virus particles are constantly circulating in the air (airborne) in different forms (within dust particles or aerosol droplets) $[5,6]$. There are some amounts of the virus in the air constantly. These amounts are insufficient to cause disease in people (the immune system of healthy humans prevents infection). However, at a higher concentration of the airborne virus, the risk of human infection increases dramatically.

Early detection of the threshold virus concentration is essential for prevention of the spread of influenza infection. Furthermore, manufacturers are going to integrate detectors of virus particle numbers into hospital air control system equipment. This review discusses different approaches for measuring the amount of influenza A virus particles in the air and assessing their infectiousness.

One of the fundamental works focused on the definition of the harmful concentration of the influenza A virus in the air is a paper by Alford, with coworkers [7]. It is cited in many recent reports [8-10]. A study was initiated to determine the minimum infectious aerosol dose and the resulting patterns of infection and illness. Observations made during experimental infections with human volunteers are particularly interesting and relevant. In studies conducted by Alford and colleagues [7], volunteers were exposed to carefully titrated aerosolized influenza virus suspensions by inhaling through a face mask. The demonstration of infection in participants of the study was achieved by recovery of infectious viruses from throat swabs, taken daily, or by seroconversion, that is, the development of neutralizing antibodies. The use of carefully titrated viral stocks enabled the determination of the minimal infectious dose by aerosol inoculation. The approximate $50 \%$ human infectious dose $\mathrm{HID}_{50}-50 \%$ human infectious dose) of virus per volunteer was from 1 to 126 $\mathrm{TCID}_{50}$ (the tissue culture 50\% infectious dose). The dose for half of the volunteers was $5 \mathrm{TCID}_{50}$. The other half of the men, who had very low or nondetectable preinoculation antibody titers, were infected with 0.6 to $3 \mathrm{TCID}_{50}$. The study reliably shows that the human infectious dose of the influenza A virus, when administered by aerosol to subjects free of serum neutralizing antibodies, is approximately $3 \mathrm{TCID}_{50}$. The approaches used in this study allow the precise number of infectious particles in the total number of particles to be determined. 
Ward, with coworkers [11], confirmed experimentally that three $\log _{10}$ copies $/ \mathrm{mL}$ corresponded to $1 \mathrm{TCID}_{50} / \mathrm{mL}$. That is, one $\mathrm{TCID}_{50} / \mathrm{mL}$ contains 1000 copies of the viral genome.

According to other reports, the aerosol infection dose for humans was about $1.95 \times 10^{3}$ viral genome copies, for approximately 300-650 copies of human influenza viruses were contained in $1 \mathrm{TCID}_{50}$, according to previous studies $[9,12]$.

During the 2009-2010 influenza season (from December to April), Yang, with coworkers [10], collected samples from a health centre, a day-care centre, and airplanes. The concentrations of airborne influenza viruses (A/PR/8/34 (H1N1) and A/swine/Minnesota/1145/2007 (H3N2)) were measured. The influenza A virus RNA was quantified by RT-PCR. Fifty percent of the samples collected contained the influenza A virus, with concentrations ranging from $5.8 \times 10^{3}$ to $3.7 \times$ $10^{4}$ genome copies per $\mathrm{m}^{3}$. The average concentration of the virus was $1.6 \pm 0.9 \times 10^{4}$ genome copies per $\mathrm{m}^{3}$, corresponding to $35.4 \pm 21.0 \mathrm{TCID}_{50}$ per $\mathrm{m}^{3}$ air. According to Yang et al. [10], $1 \mathrm{TCID}_{50}$ of $\mathrm{A} / \mathrm{PR} / 8 / 34$ (H1N1) stock was equivalent to $2.1 \times 10^{3}$ genome copies, and the ratio for the pandemic A/California/04/2009 (H1N1) strain was determined to be $452 \pm 84$ genome copies per $\mathrm{TCID}_{50}$.

Using the measured airborne virus concentration and an adult breathing rate, Yang, with colleagues [10], estimated the inhalation doses during exposures of $1 \mathrm{~h}$ (e.g., the duration of a clinical visit), $8 \mathrm{~h}$ (a workday), and $24 \mathrm{~h}$ to be $1.35 \times 10^{4}$, $1.06 \times 10^{5}$, and $3.2 \times 10^{6}$ viral particles (or $30 \pm 18,236 \pm$ 140 , and $\left.708 \pm 419 \mathrm{TCID}_{50}\right)$, respectively. Compared with the aerosol $\mathrm{HID}_{50}$ 0.6-3 $\mathrm{TCID}_{50}$ [7], these doses are adequate to induce infection. In other words, over $1 \mathrm{~h}$, the inhalation dose is estimated to be $30 \pm 18 \mathrm{TCID}_{50}$ or about 16000 particles of the influenza A virus, which is more than enough to induce infection.

\section{RT-PCR is the Principal Method for Virus Particle Determination in the Air}

To determine the concentration of virus particles in the air, a quantitative reverse transcription polymerase chain reaction (RT-PCR) method is often used [2, 10, 13-15]. Some detection limits for the influenza A virus matrix gene reported recently by PCR are $0.1 \mathrm{TCID}_{50} / \mathrm{mL}$ [16], $0.2 \mathrm{TCID}_{50} / \mathrm{mL}$ [17], and $0.006-0.02 \mathrm{TCID}_{50} / \mathrm{mL}[12]$ or $0.01-0.1 \mathrm{TCID}_{50} / \mathrm{mL}$ by LightCycler [18]. In some studies a difference in sensitivity of RT-PCR for different subtypes of the influenza A virus was observed. The RT-PCR showed sensitivity of 350 copies of $\mathrm{H} 3 \mathrm{~N} 2$ and 120 copies of $\mathrm{H} 1 \mathrm{~N} 1$ per reaction, representing the influenza A types in common circulation at the time of the study [19]. In another study [20], the influenza virus subtypes $\mathrm{H} 1$ and $\mathrm{H} 3$ have been successfully identified with equal efficiency.

However, this method does not always provide an adequate result. RT-PCR allows for the obtaining of information on the total number of viral particles, but not on the number of infectious particles. Simply testing aerosols by RT-PCR for detection of viral nucleic acid would not be sufficient to demonstrate that the viruses in fine particles remain infectious. Given the extensive debate in the literature [21, 22] and the likelihood that a large percentage of viral copies detected by molecular methods are defective [23, 24], it would be important for new studies to quantify infectious viruses and not merely measure the total viral RNA copy numbers. Based on RT-PCR assay and the influenza virus stock used for calibration, Fabian, with colleagues [9], established a ratio of 300 copies per $\mathrm{TCID}_{50}$, which is well within the previously published estimates of $100-350$ or $650[12,25]$.

\section{Distribution of Viral Particles in the Aerosol Depending on the Size of the Drops}

Alford and colleagues [7] studied the aerosol particles of influenza virus suspensions with a diameter of $1-3 \mu \mathrm{m}$. Blachere, with colleagues [26], revealed that $46 \%$ of influenza virus particles were found in the first stage of the samplers, which collected particles with a diameter of $>4 \mu \mathrm{m}$. However, $49 \%$ of the isolates were collected in the second stage, which collects particles with a diameter of $1-4 \mu \mathrm{m}$, and $4 \%$ were collected on the back-up filter, which collects particles with a diameter of $<1 \mu \mathrm{m}$. These findings indicate that $99 \%$ of the total viral particles were found in the respiratory aerosol fraction. Coughing, sneezing, talking, and breathing generate a cloud of airborne particles with diameters that can range from a few millimeters to $<1 \mu \mathrm{m}$ [27-30]. Large droplets ( $>50 \mu \mathrm{m}$ in diameter) settle on the ground almost immediately, and intermediate-sized droplets $(10-50 \mu \mathrm{m})$ settle within several minutes. Small particles $(<10 \mu \mathrm{m})$, including droplet nuclei from evaporated larger particles, can remain airborne for hours and are easily inhaled deep into the respiratory tract. Fabian, with coworkers [9], detected the influenza virus RNA in the exhaled breath of patients and found that $>99 \%$ of exhaled particles were $<5.0 \mu \mathrm{m}$ in diameter. These findings regarding the influenza virus RNA suggest that the influenza virus may be contained in fine particles generated during tidal breathing and add to the body of literature suggesting that fine particle aerosols may play a role in influenza transmission. Calculation of Stokes' law on settling rate indicated that it took $67 \mathrm{~min}$ for a particle with an aerodynamic diameter of $5 \mu \mathrm{m}$ to settle down from a $3 \mathrm{~m}$ height in the static environment; and particles of $\leq 5 \mu \mathrm{m}$ could reach as far as pulmonary alveoli [6]. Lindsley et al. [13] found that a $4-\mu \mathrm{m}$ particle takes $33 \mathrm{~min}$ to settle $1 \mathrm{~m}$ in still air, and a $1-\mu \mathrm{m}$ particle takes $8 \mathrm{~h}$; in addition, room air mixing and turbulence can keep these particles airborne even longer. Bischoff, with colleagues [31], later clarified that up to $89 \%$ of influenza virus-carrying particles were $<4.7 \mu \mathrm{m}$ in diameter. Other works confirming this data were carried out on different subtypes of the influenza A virus $[2,13,14]$.

Infectious viruses and viral RNA can be detected in both larger particles of $>5 \mu \mathrm{m}$ and smaller particles of $<5 \mu \mathrm{m}$ $[9,14,32]$. Experimental studies have demonstrated that the influenza virus can remain infectious in small particle aerosols and can transit across rooms [24, 33]. Cowling et al. [33] found that aerosol transmission (particles $<5 \mu \mathrm{m}$ ) accounted for approximately half of all transmission events. Infectious influenza was recovered in all aerosol fractions 
(5.0\% in $>4 \mu \mathrm{m}$ aerodynamic diameter, $75.5 \%$ in $1-4 \mu \mathrm{m}$, and $19.5 \%$ in $<1 \mu \mathrm{m} ; n=5$ ) [24].

The aerosol fraction that is $<4 \mu \mathrm{m}$ (the "respirable fraction") is of particular concern because it can remain airborne for an extended time and disperse throughout a room occupied by a patient with influenza. Also, particles containing influenza RNA are small enough to be drawn down into the alveolar region of the lungs. The infectious dose required for inoculation by the aerosol route relative to contact or droplet transmission is unclear, but two reviews of previous studies concluded that the infectious dose by the aerosol route is likely to be considerably lower than the infectious dose by intranasal inoculation $[21,34]$ and that aerosol inoculation results in more severe symptoms [21], presumably because aerosol particles are able to deposit deeper in the respiratory tract. However, the viability of influenza viruses in particles of different sizes and the persistence of viable airborne viruses in the environment are not yet known.

\section{Viability and Infectivity of Airborne Influenza Virus Particles Depend on Environmental Conditions}

Numerous reports have shown that the viability of different airborne viruses is dependent on environmental conditions and on the methods of collection and handling of bioaerosol samples [35]. For example, the survival of airborne influenza was shown to greatly depend on the relative humidity $(\mathrm{RH})$, as well as on ambient air temperature and ultraviolet radiation levels [34].

The infectivity of influenza virus particles is preserved depending on temperature, $\mathrm{pH}$ and salinity of the water, and UV irradiation. At $4^{\circ} \mathrm{C}$, the half-life of infectivity is about 2-3 weeks in water. Due to the conformation of the lipid bilayer, survival under normal environmental conditions should be shorter. Infectivity of the influenza virus particle is easily inactivated by all alcoholic disinfectants, chlorine and aldehydes. As far as is known, temperatures above $70^{\circ} \mathrm{C}$ destroy infectivity in a few seconds [36].

Using the newly developed guinea pig model of the influenza virus transmission, Lowen and coauthors [37] tested the impact of ambient temperature and relative humidity $(\mathrm{RH})$ on the efficiency of viral spread between hosts. When inoculated and exposed guinea pigs were housed in separate cages, transmission was found to be dependent on both temperature and $\mathrm{RH}$ [37-39]. Among the temperatures tested, transmission was highly efficient at $5^{\circ} \mathrm{C}$ but was blocked or inefficient at $30^{\circ} \mathrm{C}$. Dry conditions $(20 \%$ and $35 \% \mathrm{RH}$ ) were also found to be more favourable for spread than either intermediate $(50 \% \mathrm{RH})$ or humid $(80 \% \mathrm{RH})$ conditions. These identical results were obtained using a seasonal human strain, A/Panama/2007/1999 (H3N2) and A/Netherlands/602/2009 (H1N1). Yang and coauthors [40] propose that the effect of $\mathrm{RH}$ on virus viability is mediated by salt concentration within droplets: at high RH, physiological concentrations are maintained and viruses are relatively stable; at intermediate $\mathrm{RH}$, evaporation leads to increased salt concentration, resulting in virus inactivation; and at low
$\mathrm{RH}(<50 \%)$, salts crystallize out of solution, yielding low salt concentrations and high virion stability. Pica, with colleagues [41], tested two influenza $\mathrm{B}$ viruses transmission at low $\left(5^{\circ} \mathrm{C}\right)$ versus intermediate $\left(20^{\circ} \mathrm{C}\right)$ temperatures. The transmission was more efficient under colder conditions. Thus, transmission of human influenza viruses by a respiratory droplet or aerosol route in the guinea pig model proceeds most readily under cold, dry conditions. These findings suggested two means by which environmental factors could drive the wintertime seasonality of influenza.

Atkinson and Wein [8] created a mathematical model that describes aerosol (i.e. droplet-nuclei) and contact transmission of influenza A virus subtype H5N1 within a household containing one infected. It was demonstrated that in addition to the concentration of particles in the air that a person inhales, time plays a determining role in the influenza virus infection.

\section{Relationship between the Influenza Virus Subtypes and Virus Air Transmission}

Is there any difference in the influenza virus transmission depending on the virus subtype? In scientific publications, contradictory data obtained on laboratory animals only are presented. Studies using the guinea pig and the ferret models have demonstrated differences of the influenza virus transmission for different strains or genetic compositions by the aerosol route $[37,38,42]$.

In the study by Chou, with coworkers [43], the aerosol transmission rate of an influenza virus A/California/04/09 (H1N1) and another H1N1 strain, A/Puerto Rico/8/34, was measured as the percentage of susceptible guinea pigs infected following exposure to inoculated animals. A/California/04/09 was found to spread more efficiently. Differences in the nucleotide sequence of the $M$ segment of the virus genome were found to cause a difference in the aerosol transmission rate. Interestingly, the Eurasian avian-like swine viruses, which possess an $M$ segment closely related to that of the A/California/04/09 (H1N1) virus, are not transmitted efficiently in humans [44].

Pearce, with colleagues [45], characterized four A(H3N$2) \mathrm{v}$ viruses isolated in 2009, 2010, and 2011, from patients with uncomplicated upper respiratory tract illnesses (A/ Kansas/13/2009 (KS/09), A/Minnesota/11/10 (MN/10), A/ Pennsylvania/14/, 10 (PA/10), and A/Indiana/08/11 (IN/11)) and demonstrated that the 2010-2011 A(H3N2)v viruses replicated efficiently in ferrets and readily transmitted in both the direct-contact (DC) and respiratory-droplet (RD) models, whereas the 2009 A(H3N2)v virus exhibited efficient DC transmission but less efficient RD transmission. Typically, the difference in efficiency of the infection of animals in all experiments was a delay in infection of $0.5-1$ day. In this context, it is difficult to claim that a clear relationship between the influenza virus subtypes and air virus transmission can be revealed. Authors do not exclude that other genetic requirements must be met in order for the transfer to take place. 
The study by Chan, with colleagues [46], has demonstrated that the sensitivity of the commercially available rapid influenza antigen detection tests did not depend on the subtype influenza virus. The analytical sensitivity of the detection tests for swine influenza virus $\left(\mathrm{TCID}_{50} \log _{10} 3.3-4.7\right)$ was comparable with that of seasonal influenza A/HK/403946/09 (H1N1) virus $\left(\mathrm{TCID}_{50} \log _{10} 4.0-4.5\right)$. Thus, differences between subtypes were not identified.

Clear correlation and dependence of the number of diseased subjects on the concentration of the influenza virus in the air were shown in various models. For example, a relationship between the number of infected pigs and the influenza detection in the air was identified in a study on a single H1N1 viral strain [47]. The chance of detection of an influenza positive air sample increased 2.2 times per each additional nasal secretion by a sick pig. This suggests that the risk of aerosolization and perhaps aerosol transmission increases as the number of infected pigs increase.

\section{Exhaled Breath of Healthy Subjects also Contains Influenza Virus Particles}

It is important to consider that the air exhaled by the healthy person also contains influenza virus particles. In studies of particles exhaled by healthy subjects during tidal breathing, researchers reported concentrations from 1 to over $1 \times 10^{4}$ particles per liter, with the majority of the particles being less than $0.3 \mu \mathrm{m}$ in diameter $[29,48,49]$. One of these studies also reported that $55 \%$ of the population studied exhaled $>98 \%$ of the particles in the air volume investigated and concluded that these subjects, classified as high producers, could, over time, exhale more particles during normal tidal breathing than during relatively infrequent coughing or sneezing events [49]. Concentrations in exhaled breath samples ranged from $<48$ to 300 influenza virus RNA copies per filter in the positive samples, corresponding to exhaled breath generation rates ranging from $<3.2$ to 20 influenza virus RNA copies per minute. Total particle concentrations ranged from 67 to $8.5 \times$ $10^{3}$ particles per liter of air.

\section{Conclusions}

The human infectious dose of the influenza A virus, when administered by aerosol to subjects free of serum neutralizing antibodies, ranges between $1.95 \times 10^{3}$ and $3.0 \times 10^{3}$ viral particles.

To determine the concentration of virus particles in the air, the RT-PCR method is often used. However, RT-PCR analysis provides information on the total number of viral particles, but not on the number of infectious particles. Influenza virus genomic segments are chosen and packaged at random, whereby only parts of the virions are infectious.

According to various scientific publications, data about the influence of the virus subtype on the effectiveness of influenza transmission are contradictory. The subtype-specific differences in influenza virus transmission were observed in animal models, and recipient animals did not exhibit a preexisting influenza virus specific immune response. However, the pathogenicity of a virus subtype depends on the immune status of the recipients (human). The second point is (when) how recently viruses of the same subtype circulated in the population previously.

Therefore, it is important to consider that the risk of acquiring influenza is determined by both the concentration of the influenza A virus infectious particles (not their total amount) in the air and the immune status of the exposed individuals.

\section{Conflict of Interests}

The authors declare that there is no conflict of interests regarding the publication of this paper.

\section{Acknowledgment}

This work was supported by LG Electronics Inc. (Republic of Korea).

\section{References}

[1] T. Vega, J. E. Lozano, T. Meerhoff et al., "Influenza surveillance in Europe: establishing epidemic thresholds by the Moving Epidemic Method," Influenza and other Respiratory Viruses, vol. 7, no. 4, pp. 546-558, 2013.

[2] G. Cao, F. M. Blachere, W. G. Lindsley, J. D. Noti, and D. H. Beezhold, "Development of a methodology to detect viable airborne virus using personal aerosol samplers," EPA/600/R10/127, Environmental Protection Agency, Washington, DC, USA, 2010.

[3] I. Marois, A. Cloutier, É. Garneau, and M. V. Richter, "Initial infectious dose dictates the innate, adaptive, and memory responses to influenza in the respiratory tract," Journal of Leukocyte Biology, vol. 92, no. 1, pp. 107-121, 2012.

[4] J. McDevitt, S. Rudnick, M. First, and J. Spengler, "Role of absolute humidity in the inactivation of influenza viruses on stainless steel surfaces at elevated temperatures," Applied and Environmental Microbiology, vol. 76, no. 12, pp. 3943-3947, 2010.

[5] C. B. Hall, "The spread of influenza and other respiratory viruses: complexities and conjectures," Clinical Infectious Diseases, vol. 45, no. 3, pp. 353-359, 2007.

[6] R. Tellier, "Aerosol transmission of influenza A virus: a review of new studies," Journal of the Royal Society Interface, vol. 6, supplement 6, pp. S783-S790, 2009.

[7] R. H. Alford, J. A. Kasel, P. J. Gerone, and V. Knight, "Human influenza resulting from aerosol inhalation.", Proceedings of the Society for Experimental Biology and Medicine, vol. 122, no. 3, pp. 800-804, 1966.

[8] M. P. Atkinson and L. M. Wein, "Quantifying the routes of transmission for pandemic influenza," Bulletin of Mathematical Biology, vol. 70, no. 3, pp. 820-867, 2008.

[9] P. Fabian, J. J. McDevitt, W. H. DeHaan et al., "Influenza virus in human exhaled breath: an observational study," PLOS ONE, vol. 3, no. 7, Article ID e2691, 2008.

[10] W. Yang, S. Elankumaran, and L. C. Marr, "Concentrations and size distributions of airborne influenza A viruses measured indoors at a health centre, a day-care centre and on aeroplanes," Journal of the Royal Society Interface, vol. 8, no. 61, pp. 1176-1184, 2011. 
[11] C. L. Ward, M. H. Dempsey, C. J. A. Ring et al., "Design and performance testing of quantitative real time PCR assays for influenza A and B viral load measurement," Journal of Clinical Virology, vol. 29, no. 3, pp. 179-188, 2004.

[12] L. J. R. Van Elden, M. Nijhuis, P. Schipper, R. Schuurman, and A. M. van Loon, "Simultaneous detection of influenza viruses A and B using real-time quantitative PCR," Journal of Clinical Microbiology, vol. 39, no. 1, pp. 196-200, 2001.

[13] W. G. Lindsley, F. M. Blachere, K. A. Davis et al., "Distribution of airborne influenza virus and respiratory syncytial virus in an urgent care medical clinic," Clinical Infectious Diseases, vol. 50, no. 5, pp. 693-698, 2010.

[14] W. G. Lindsley, F. M. Blachere, R. E. Thewlis et al., "Measurements of airborne influenza virus in aerosol particles from human coughs," PLoS ONE, vol. 5, no. 11, Article ID e15100, 2010.

[15] K. W. Moon, E. H. Huh, and H. C. Jeong, "Seasonal evaluation of bioaerosols from indoor air of residential apartments within the metropolitan area in South Korea," Environmental Monitoring and Assessment, vol. 186, no. 4, pp. 2111-2120, 2014.

[16] B. Schweiger, I. Zadow, R. Heckler, H. Timm, and G. Pauli, "Application of a fluorogenic PCR assay for typing and subtyping of influenza viruses in respiratory samples," Journal of Clinical Microbiology, vol. 38, no. 4, pp. 1552-1558, 2000.

[17] R. A. M. Fouchier, T. M. Bestebroer, S. Herfst, L. Van der Kemp, G. F. Rimmelzwaan, and A. D. M. E. Osterhaus, "Detection of influenza a viruses from different species by PCR amplification of conserved sequences in the matrix gene," Journal of Clinical Microbiology, vol. 38, no. 11, pp. 4096-4101, 2000.

[18] S. K. Poddar, "Detection of type and subtypes of influenza virus by hybrid formation of FRET probe with amplified target DNA and melting temperature analysis," Journal of Virological Methods, vol. 108, no. 2, pp. 157-163, 2003.

[19] B. Stone, J. Burrows, S. Schepetiuk et al., "Rapid detection and simultaneous subtype differentiation of influenza A viruses by real time PCR," Journal of Virological Methods, vol. 117, no. 2, pp. 103-112, 2004.

[20] C. Tseng, L. Chang, and C. Li, "Detection of airborne viruses in a pediatrics department measured using real-time qPCR coupled to an air-sampling filter method," Journal of Environmental Health, vol. 73, no. 4, pp. 22-28, 2010.

[21] R. Tellier, "Review of aerosol transmission of influenza A virus," Emerging Infectious Diseases, vol. 12, no. 11, pp. 1657-1662, 2006.

[22] G. Brankston, L. Gitterman, Z. Hirji, C. Lemieux, and M. Gardam, "Transmission of influenza A in human beings," The Lancet Infectious Diseases, vol. 7, no. 4, pp. 257-265, 2007.

[23] P. Fabian, J. J. McDevitt, E. A. Houseman, and D. K. Milton, "Airborne influenza virus detection with four aerosol samplers using molecular and infectivity assays: considerations for a new infectious virus aerosol sampler," Indoor Air, vol. 19, no. 5, pp. 433-441, 2009.

[24] J. D. Noti, W. G. Lindsley, F. M. Blachere et al., "Detection of infectious influenza virus in cough aerosols generated in a simulated patient examination room," Clinical Infectious Diseases, vol. 54, no. 11, pp. 1569-1577, 2012.

[25] Z. Wei, M. Mcevoy, V. Razinkov et al., "Biophysical characterization of influenza virus subpopulations using field flow fractionation and multiangle light scattering: correlation of particle counts, size distribution and infectivity," Journal of Virological Methods, vol. 144, no. 1-2, pp. 122-132, 2007.
[26] F. M. Blachere, W. G. Lindsley, T. A. Pearce et al., "Measurement of airborne influenza virus in a hospital emergency department," Clinical Infectious Diseases, vol. 48, no. 4, pp. 438-440, 2009.

[27] R. G. Loudon and R. M. Roberts, "Droplet expulsion from the respiratory tract," The American Review of Respiratory Disease, vol. 95, no. 3, pp. 435-442, 1967.

[28] M. W. Jennison, "Atomizing of mouth and nose secretions into the air as revealed by high-speed photography," in Aerobiology, F. R. Moulton, Ed., pp. 106-128, American Association for the Advancement of Science, Washington, DC, USA, 1942.

[29] R. S. Papineni and F. S. Rosenthal, "The size distribution of droplets in the exhaled breath of healthy human subjects," Journal of Aerosol Medicine: Deposition, Clearance, and Effects in the Lung, vol. 10, no. 2, pp. 105-116, 1997.

[30] C. Y. H. Chao, M. P. Wan, L. Morawska et al., "Characterization of expiration air jets and droplet size distributions immediately at the mouth opening," Journal of Aerosol Science, vol. 40, no. 2, pp. 122-133, 2009.

[31] W. E. Bischoff, K. Swett, I. Leng, and T. R. Peters, "Exposure to influenza virus aerosols during routine patient care," The Journal of Infectious Diseases, vol. 207, no. 7, pp. 1037-1046, 2013.

[32] D. K. Milton, M. P. Fabian, B. J. Cowling, M. L. Grantham, and J. J. McDevitt, "Influenza virus aerosols in human exhaled breath: particle size, culturability, and effect of surgical masks," PLoS Pathogens, vol. 9, no. 3, Article ID e1003205, 2013.

[33] B. J. Cowling, D. K. Ip, V. J. Fang et al., "Aerosol transmission is an important mode of influenza A virus spread," Nature Communications, vol. 4, article 1935, 2013.

[34] T. P. Weber and N. I. Stilianakis, "Inactivation of influenza A viruses in the environment and modes of transmission: a critical review," Journal of Infection, vol. 57, no. 5, pp. 361-373, 2008.

[35] S. A. Sattar and M. K. Ijaz, "Airborne viruses," in Manual of Environmental Microbiology, C. J. Hurst, R. L. Crawford, M. J. McInerney, G. R. Knudsen, and L. D. Stetzenbach, Eds., pp. 871883, ASM Press, Washington, DC, USA, 2002.

[36] L. Guertler, "Virology of human influenza," in Influenza Report, B. S. Kamps, C. Hoffmann, and W. Preiser, Eds., pp. 87-91, Flying, Paris, France, 2006.

[37] A. C. Lowen, S. Mubareka, T. M. Tumpey, A. García-Sastre, and P. Palese, "The guinea pig as a transmission model for human influenza viruses," Proceedings of the National Academy of Sciences of the United States of America, vol. 103, no. 26, pp. 9988-9992, 2006.

[38] A. C. Lowen, S. Mubareka, J. Steel, and P. Palese, "Influenza virus transmission is dependent on relative humidity and temperature," PLoS Pathogens, vol. 3, no. 10, pp. 1470-1476, 2007.

[39] J. Steel, P. Palese, and A. C. Lowen, "Transmission of a 2009 pandemic influenza virus shows a sensitivity to temperature and humidity similar to that of an H3N2 seasonal strain," Journal of Virology, vol. 85, no. 3, pp. 1400-1402, 2011.

[40] W. Yang, S. Elankumaran, and L. C. Marr, "Relationship between humidity and influenza' s seasonality, PLoS ONE, vol. 7, no. 10, Article ID e46789, 2012.

[41] N. Pica, Y. Chou, N. M. Bouvier, and P. Palese, "Transmission of influenza B viruses in the Guinea pig," Journal of Virology, vol. 86, no. 8, pp. 4279-4287, 2012.

[42] N. van Hoeven, C. Pappas, J. A. Belser et al., "Human HA and polymerase subunit PB2 proteins confer transmission of an avian influenza virus through the air," Proceedings of the National Academy of Sciences of the United States of America, vol. 106, no. 9, pp. 3366-3371, 2009. 
[43] Y. Chou, R. A. Albrecht, N. Pica et al., "The m segment of the 2009 new pandemic H1N1 influenza virus is critical for its high transmission efficiency in the Guinea pig model," Journal of Virology, vol. 85, no. 21, pp. 11235-11241, 2011.

[44] T. T. Lam, H. Zhu, J. Wang et al., "Reassortment events among swine influenza a viruses in China: implications for the origin of the 2009 influenza pandemic," Journal of Virology, vol. 85, no. 19, pp. 10279-10285, 2011.

[45] M. B. Pearce, A. Jayaraman, C. Pappas et al., "Pathogenesis and transmission of swine origin $\mathrm{A}(\mathrm{H} 3 \mathrm{~N} 2) \mathrm{v}$ influenza viruses in ferrets," Proceedings of the National Academy of Sciences of the United States of America, vol. 109, no. 10, pp. 3944-3949, 2012.

[46] K. H. Chan, S. T. Lai, L. L. M. Poon, Y. Guan, K. Y. Yuen, and J. S. M. Peiris, "Analytical sensitivity of rapid influenza antigen detection tests for swine-origin influenza virus (H1N1)," Journal of Clinical Virology, vol. 45, no. 3, pp. 205-207, 2009.

[47] C. A. Corzo, A. Romagosa, S. A. Dee, M. R. Gramer, R. B. Morrison, and M. Torremorell, "Relationship between airborne detection of influenza A virus and the number of infected pigs," Veterinary Journal, vol. 196, no. 2, pp. 171-175, 2013.

[48] C. I. Fairchild and J. F. Stampfer, "Particle concentration in exhaled breath," The American Industrial Hygiene Association Journal, vol. 48, no. 11, pp. 948-949, 1987.

[49] D. A. Edwards, J. C. Man, P. Brand et al., "Inhaling to mitigate exhaled bioaerosols," Proceedings of the National Academy of Sciences of the United States of America, vol. 101, no. 50, pp. 17383-17388, 2004. 

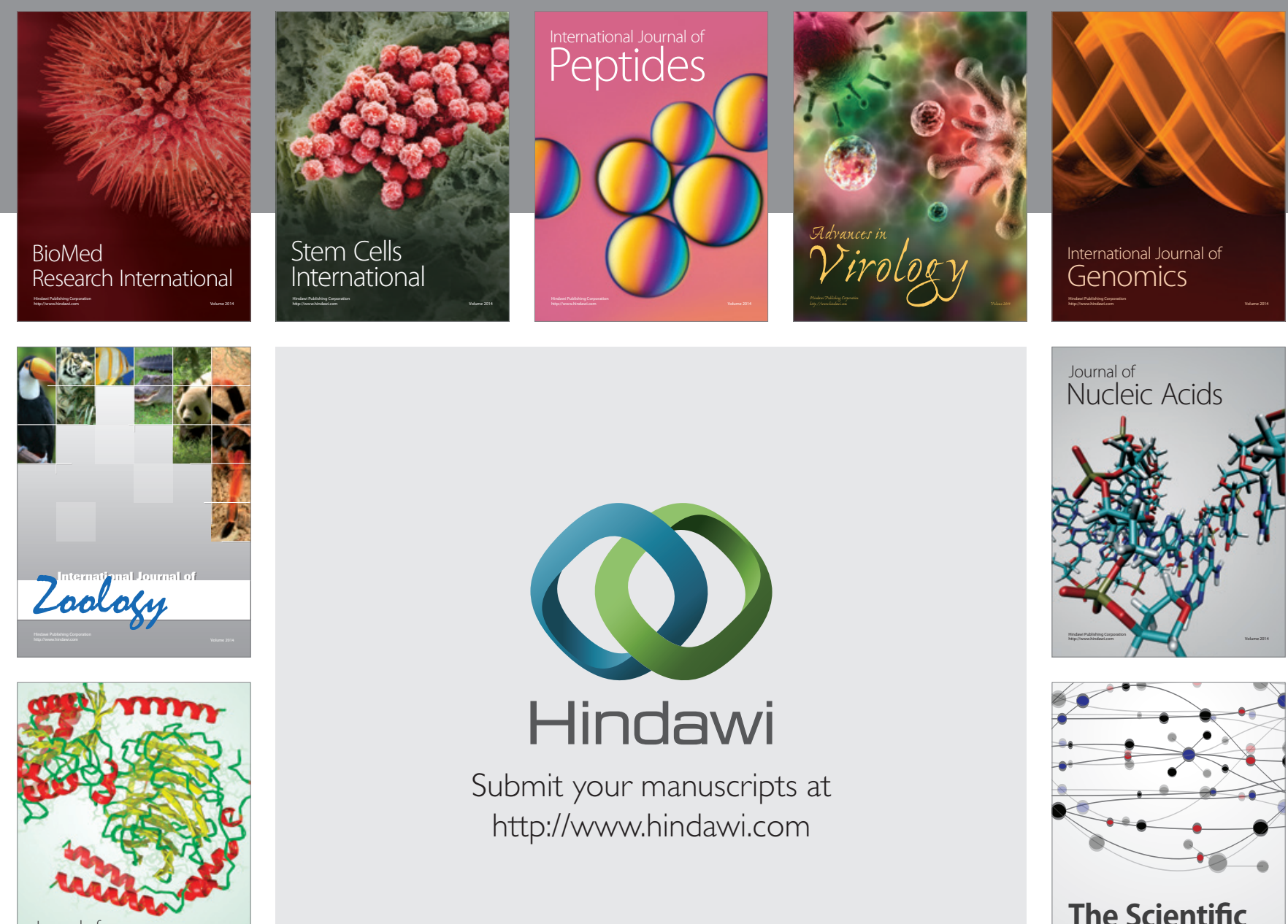

Submit your manuscripts at

http://www.hindawi.com

Journal of
Signal Transduction
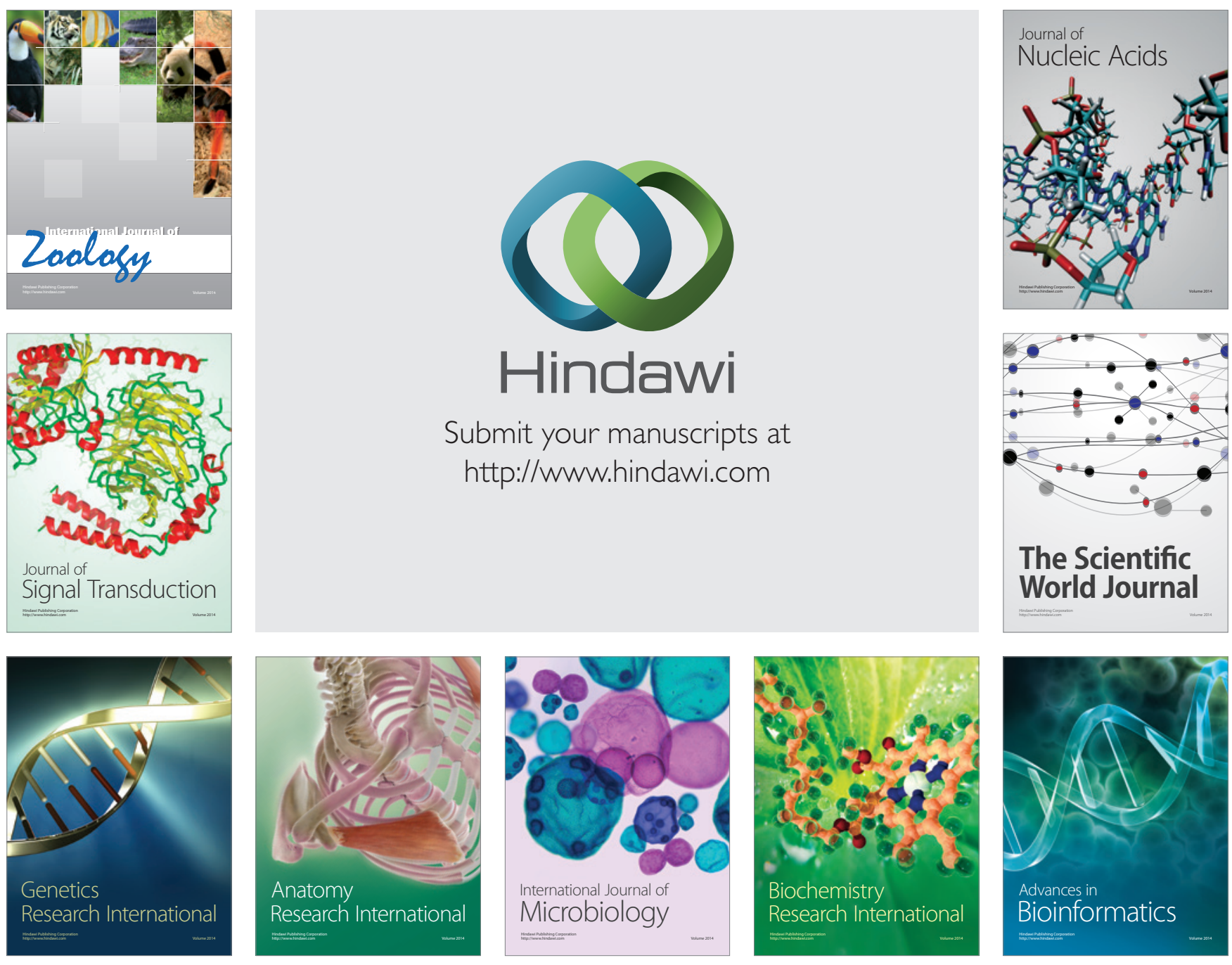

The Scientific World Journal
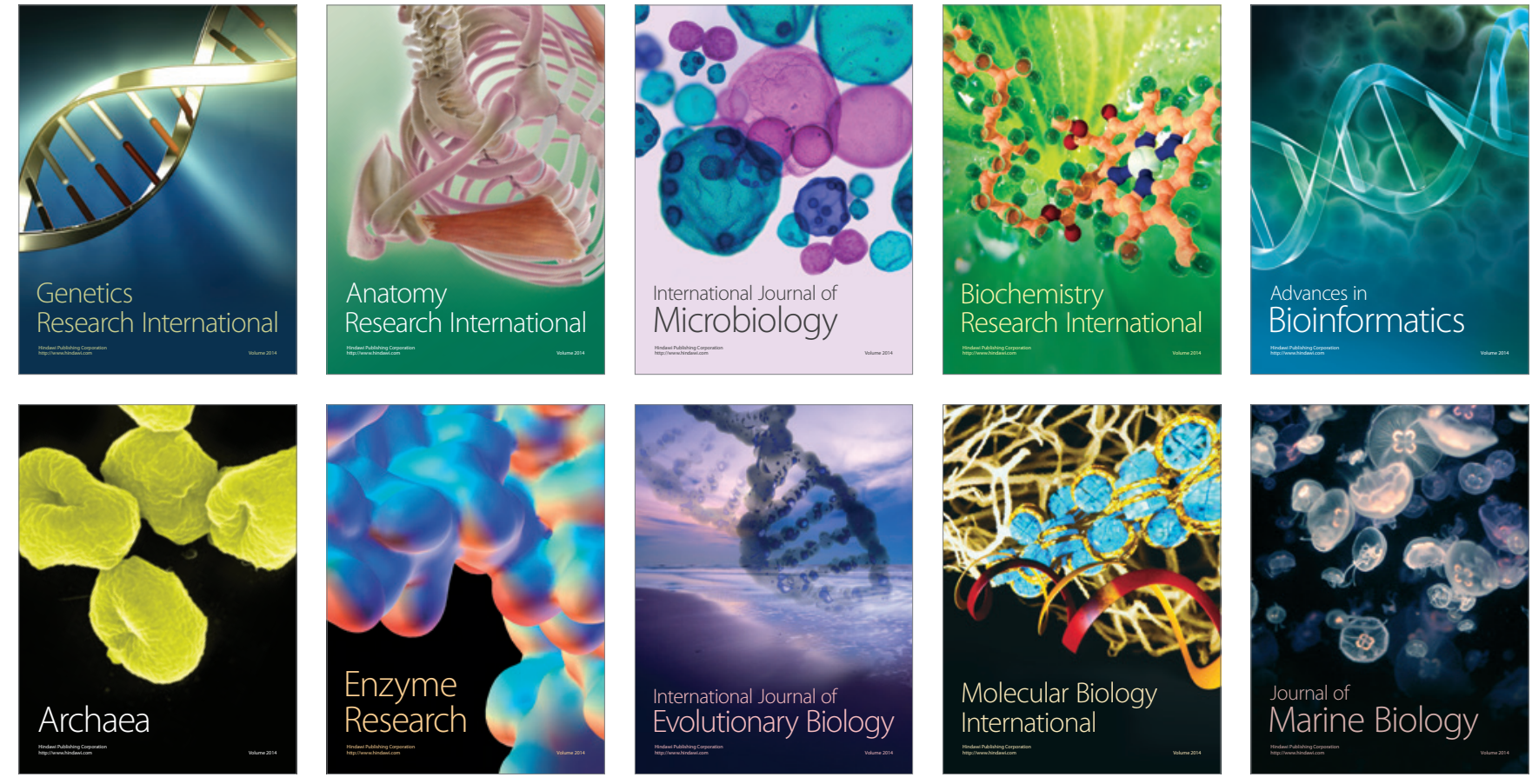